\title{
BMJ Open Interaction of physical activity on the association of obesity-related measures with multimorbidity among older adults: a population-based cross- sectional study in India
}

\author{
Shobhit Srivastava (D) , ${ }^{1}$ Vinod Joseph K J (D) , ${ }^{2}$ Drishti Dristhi, ${ }^{2}$ T Muhammad (i) ${ }^{3}$
}

To cite: Srivastava S, Joseph K J V, Dristhi D, et al. Interaction of physical activity on the association of obesity-related measures with multimorbidity among older adults: a populationbased cross-sectional study in India. BMJ Open 2021;11:e050245. doi:10.1136/ bmjopen-2021-050245

- Prepublication history for this paper is available online. To view these files, please visit the journal online (http://dx.doi. org/10.1136/bmjopen-2021050245).

Received 15 February 2021 Accepted 29 April 2021

Check for updates

(C) Author(s) (or their employer(s)) 2021. Re-use permitted under CC BY-NC. No commercial re-use. See rights and permissions. Published by BMJ.

${ }^{1}$ Department of Mathematical Demography and Statistics, International Institute for Population Sciences, Mumbai, Maharashtra, India

${ }^{2}$ Department of Public Health and Mortality Studies, International Institute for Population Sciences, Mumbai, Maharashtra, India

${ }^{3}$ Department of Population

Policies and Programs,

International Institute for

Population Sciences, Mumbai,

Maharashtra, India

Correspondence to

T Muhammad;

muhammad@iips.net

\section{ABSTRACT}

Objective To explore the associations between obesityrelated measures and multimorbidity among older Indian adults and the interactive effects of physical activity in those associations.

Design A cross-sectional study was conducted using large representative survey data.

Setting and participants The present study used data from the Longitudinal Aging Study in India (LASI) conducted during 2017-2018. Participants included 15098 male and 16366 female older adults aged 60 years and above in India.

Primary and secondary outcome measures The outcome variable was multimorbidity among older adults coded as no and yes. Descriptive statistics along with bivariate analysis are presented in the paper. Additionally, binary logistic regression analysis was used to fulfil the study objectives.

Results About $24 \%$ of older adults in the LASI cohort suffered from multimorbidity. Older adults who were overweight/obese (adjusted OR (AOR): 1.61, Cl 1.48 to 1.74), had high-risk waist circumference (AOR: 1.66, $\mathrm{Cl} 1.52$ to 1.80 ) and had high-risk waist to hip ratio (AOR: 1.45 , Cl 1.33 to 1.59) were significantly more likely to suffer from multimorbidity compared with their counterparts. Older adults who were obese and physically inactive had significantly increased odds of suffering from multimorbidity compared with older adults who were obese and physically active. Similarly, older adults with high-risk waist circumference (AOR: 1.30, Cl 1.11 to 1.53) and high-risk waist to hip ratio (AOR: $1.32, \mathrm{Cl} 1.20$ to 1.46) along with being physically inactive had significantly higher odds of suffering from multimorbidity in comparison with older adults with high-risk waist circumference and waist to hip ratio along with being physically active. Conclusion While developing health strategies for older adults, physical activity needs to be recognised as a way of minimising comorbidities. Further, the study highlights the importance of using multiple obesity-related measures to predict chronic conditions in the older population.

\section{BACKGROUND}

Considering the demographic shift towards population ageing in India, the share of
Strengths and limitations of this study

- The study used a large nationally representative sample of older population.

- Objectively measured obesity-related information has been used in the study.

- The cross-sectional design is a limitation of the study as it is impossible to establish the observed directions of the relationships.

- The study used a relatively simple definition of counting diseases for measuring multimorbidity.

people aged 60 and above is projected to increase from $8.6 \%$ in 2011 to $20 \%$ in $2050 .{ }^{1}$ India's demographic structure is likely to shift from a young to an ageing population beyond the 2030's. ${ }^{2}$ On the other hand, the prevalence of overweight and obesity among adults worldwide has risen from approximately $27.5 \%$ in 1980 to $39 \%$ in $2016 .{ }^{3}$ Although the prevalence of overweight/obesity is comparatively lower among older adults than the $18-55$ age groups, the increasing trend in the prevalence of overweight/obesity over the past four decades is similar among both age groups.

Traditionally healthcare delivery was built and remained typically centred on the treatment of single diseases. Over the past few decades on-site of the demographic and epidemiological transition, the growing number of elderly has become a considerable challenge to healthcare delivery as more than half of the elderly have at least two chronic conditions. ${ }^{45}$ The WHO defines multimorbidity as 'the coexistence of two or more chronic conditions in the same individual'. ${ }^{6}$ Changes in lifestyle and behavioural factors and inactivity and overeating result in impaired body systems functions and culminate in multimorbidity and increased 
incidence of non-communicable diseases, including cardiovascular diseases, obesity, diabetes and cancer. ${ }^{78}$

The negative impacts of overweight/obesity on cardiovascular diseases, diabetes, hypertension and multimorbidity are well studied ${ }^{9}{ }^{10}$ and accounted for 4.0 million deaths globally. ${ }^{11}$ Again, deprivation and health behaviours are significant predictors of multimorbidity. The public health efforts to modify the social determinants and foster healthy lifestyles can minimise the risk of multimorbidity. ${ }^{12}$ The increased risk of multimorbidity in young adults and the growing numbers of elderly may contribute to the health and social care burden in the coming years. ${ }^{13}$ Sufficient physical activity across the life course is the key requirement for healthy ageing and a predictor of reduced mortality. ${ }^{1415}$ It is widely recognised that the immune system is influenced by physical activity. ${ }^{16}$ Increased inactivity across the lifespan due to lifestyle changes and decline in physical activity with ageing might reduce immunity in old ages. ${ }^{8}$

Several studies have highlighted the association between physical activity and overweight/obesity among older adults. ${ }^{17-20}$ Physical inactivity and impaired physical mobility are the primary reasons for overweight/obesity among the elderly due to decreased metabolic rate and body composition changes. ${ }^{21} 22$ Physical inactivity and poor health behaviours like obesity are major risk factors common to several diseases. ${ }^{23}$ Regular physical activity is known to improve life quality, prevent various chronic diseases and reduce risk of premature death. ${ }^{24-26}$ Studies also suggest that better physical activity could be the key to improving outcomes for older adults with multimorbidity. Physical activity should be promoted as an essential strategy to mitigate the growing burden of multimorbidity among older adults globally. Fulfilling the needs for healthcare services, physical activity, social protection for the elderly, protecting their rights and enabling them to contribute to the development process should be priorities in India's coming years.

Furthermore, previous studies revealed that multimorbidity is associated with sociodemographic characteristics such as age, sex, residence and economic status. In developed countries, multimorbidity is more prevalent among lower socioeconomic groups, ${ }^{427}$ while in the context of a developing country multimorbidity is more among the wealthier. ${ }^{28}{ }^{29}$ Studies show that women and older adults have a higher chance of multimorbidity than men and younger adults. ${ }^{28} 30{ }^{31}$ Like socioeconomic status, there was an assumption that the multimorbidity burden exists only in developed and industrialised countries. Yadav and Arokiasamy ${ }^{32}$ demonstrated the burden of multimorbidity as a major health concern especially in lower-middleincome countries, where social, behavioural and lifestyle patterns are altered with rising levels of urbanisation and industrialisation. Evidence shows the urban place of residence is associated with risk of multimorbidity. ${ }^{283}$

No previous study has looked into the interactions between physical activity, obesity measures and associated multimorbidity among older adults in the Indian context to the best of our knowledge. This study using the latest available data may provide new insights on this demanding area and highlight the relative merits of strategies to encourage physical activity among older adults. Thus, the present study explores the associations between obesity measures, physical activity and multimorbidity among older Indian adults using large nationally representative data.

\section{MATERIALS AND METHODS}

The present study used data from the Longitudinal Aging Study in India (LASI) baseline wave (wave 1) conducted during 2017-2018 in India. The survey is a joint undertaking of the Harvard TH Chan School of Public Health, the International Institute for Population Sciences and the University of Southern California. The nationally representative longitudinal survey collects vital information on the physical, social and cognitive well-being of India's older adults, which will be followed up for 25 years. The data of over 72000 individuals aged 45 and above along with their spouses (irrespective of age) are collected across all states and union territories of India. The sample is based on a multistage stratified cluster sample design, including three and four distinct stages of rural and urban area selection, respectively. The survey provides scientific insights and facilitates a harmonised design which helps in comparing with parallel international studies. Further, the details of sample design, survey instruments, fieldwork, data collection and processing, and response rates are publicly available in the LASI report found on the LASI website. ${ }^{34}$

Participants of the study consist of 15098 male and 16366 female older adults aged 60 years and above in India. Further, the sample of overweight and high-risk waist circumference and waist to hip ratio may differ from the total sample as some of the older adults did not provide consent for measurements. ${ }^{34}$ The survey agencies that conducted the field survey for data collection have collected prior consent from the respondents.

\section{Variable description}

\section{Outcome description}

The outcome variable was coded as binary, that is, multimorbidity (no/yes). Multimorbidity conditions refer to the presence of two or more chronic diseases, which include hypertension, chronic heart diseases, stroke, any chronic lung disease, diabetes, cancer or malignant tumour, any bone/joint disease, neurological/psychiatric disease, or high cholesterol. ${ }^{34}$ The diseases were self-reported, ${ }^{35}$ as assessed using the question 'Has any health professional ever diagnosed you with the following chronic conditions or diseases?'

\section{Explanatory variables}

The variables controlled for in the present study were taken into consideration after an extensive literature review. Overweight/obesity was categorised as no and 
yes. Respondents with a body mass index of 25 and above were categorised as obese/overweight. High-risk waist circumference was categorised as no and yes. ${ }^{36}$ Male and female respondents who have waist circumferences of more than $102 \mathrm{~cm}$ and $88 \mathrm{~cm}$, respectively, were considered to have high-risk waist circumference. ${ }^{37}$ High-risk waist to hip ratio was categorised as no and yes. Male and female respondents who have a waist to hip ratio of more than or equal to 0.90 and $0.85 \mathrm{~cm}$, respectively, were considered to have a high-risk waist to hip ratio. ${ }^{37}$ Physical activity status was categorised as frequent (every day), rare (more than once a week, once a week, one to three times in a month) and never. The question through which physical activity was assessed was 'How often do you take part in sports or vigorous activities, such as running or jogging, swimming, going to a health center or gym, cycling, or digging with a spade or shovel, heavy lifting, chopping, farm work, fast bicycling, cycling with loads?'

Age was categorised as young old (60-69 years), oldold (70-79 years) and oldest-old (80+ years). Education was categorised as no education/primary schooling not completed, primary completed, secondary completed, and higher and above. Marital status was categorised as currently married, widowed and others (separated/never married/divorced). Working status was categorised as working, retired and not working. Tobacco and alcohol consumption was coded as no and yes.

The monthly per capita consumption expenditure (MPCE) quintile was measured using household consumption data. Sets of 11 and 29 questions on the expenditures on food and non-food items, respectively, were used to canvas the sample households. Food expenditure was collected based on a reference period of 7 days, and non-food expenditure was collected based on reference periods of 30 days and 365 days. Food and non-food expenditures have been standardised to the 30-day reference period. ${ }^{34}$ The monthly per capita consumption expenditure is computed and used as the summary measure of consumption. The variable was then divided into five quintiles, that is, from poorest to richest. Religion was categorised as Hindu, Muslim, Christian and Others. Caste was categorised as Scheduled Tribe, Scheduled Caste, Other Backward Class and others. The Scheduled Caste includes the "untouchables', a group of population that is socially segregated and financially/economically by their low status as per Hindu caste hierarchy. The Scheduled Caste and Scheduled Tribe are among the most disadvantaged socioeconomic groups in India. The Other Backward Class is the group of people who were identified as 'educationally, economically and socially backward'. The Other Backward Class is considered low in the traditional caste hierarchy but is not considered untouchables. The 'other' caste category is identified as having higher social status. Place of residence was categorised as rural and urban. Region was categorised as North, Central, East, Northeast, West and South.

\section{Statistical analysis}

Descriptive statistics along with bivariate analysis are presented in the paper. $\chi^{2}$ test was used to compare the intergroup differences and report the significance level. ${ }^{38} 39$ Additionally, binary logistic regression analysis ${ }^{40}$ was used to establish the association between outcome variable (multimorbidity) and other explanatory variables.

The binary logistic regression model is usually put into a more compact form as follows:

$$
\operatorname{Logit}[\mathrm{P}(\mathrm{Y}=1)]=\beta_{0}+\beta * X+\epsilon
$$

The parameter $\beta_{0}$ estimates the log odds of the multimorbidity for the reference group, while $\beta$ estimates the maximum likelihood, the differential log odds of the multimorbidity associated with a set of predictors $\mathrm{X}$, as compared with the reference group, and $\epsilon$ represents the residual in the model.

The multivariate analysis had four models to explain the adjusted estimates. Model 1 provides the adjusted estimates for the control variables. Model 2, model 3 and model 4 provide the interaction effects ${ }^{41} 42$ for obesity indicator and physical activity status with multimorbidity among older adults. An 'interaction variable' is a variable constructed from an original set of variables to try to represent either all of the interaction present or some part of it. In exploratory statistical analyses, it is common to use products of original variables as the basis of testing whether the interaction is present, with the possibility of substituting other more realistic interaction variables at a later stage. When there are more than two explanatory variables, several interaction variables are constructed, with pairwise products representing pairwise interactions and higher-order products representing higher-order interactions. ${ }^{41-44}$

Thus, for a response $\mathrm{Y}$ and two variables $\mathrm{x}_{1}$ and $x_{2}$ an additive model would be:

$\mathrm{Y}=\alpha+\beta_{1} \mathrm{x}_{1}+\beta_{2} \mathrm{x}_{2}+\varepsilon_{0}$

In contrast to this,

$\mathrm{Y}=\alpha+\beta_{1} \mathrm{x}_{1}+\beta_{2} \mathrm{x}_{2}+\left(\beta_{3} \mathrm{x}_{\mathrm{s}} * \mathrm{x}_{\mathrm{a}}\right) \varepsilon_{0}$

where $\mathrm{Y}$ is the dependent variable (multimorbidity) and $\alpha$ is intercept, $x_{1}$ is individual-level independent variable, $x_{2}$ is individual-level independent variable, $x_{a}$ is obesity indicator, $\mathrm{x}_{\mathrm{s}}$ is physical activity, $\left(\beta_{3} \mathrm{x}_{\mathrm{s}} * \mathrm{x}_{\mathrm{a}}\right)$ is the interaction of obesity indicator and psychical activity, and $\varepsilon_{0}$ is error. Often, models are presented without the interaction term $d\left(x_{1} * x_{2}\right)$, but this confounds the main effect and the interaction effect (ie, without specifying the interaction term, it is possible that any main effect found is actually due to interaction). ${ }^{45}$

\section{Patient and public involvement}

No patients were involved.

\section{RESULTS}

Table 1 presents the sociodemographic and economic profile of older adults in the LASI cohort. The table reveals that about one-fifth of the older adults were 
Table 1 Sociodemographic and economic profile of older adults in the LASI cohort, India

\begin{tabular}{lrl}
\hline Background characteristics & Sample & $\%$ \\
\hline Obese/overweight $^{*}$ & & \\
No & 21833 & 77.8 \\
Yes & 6217 & 22.2
\end{tabular}

High-risk waist circumference*

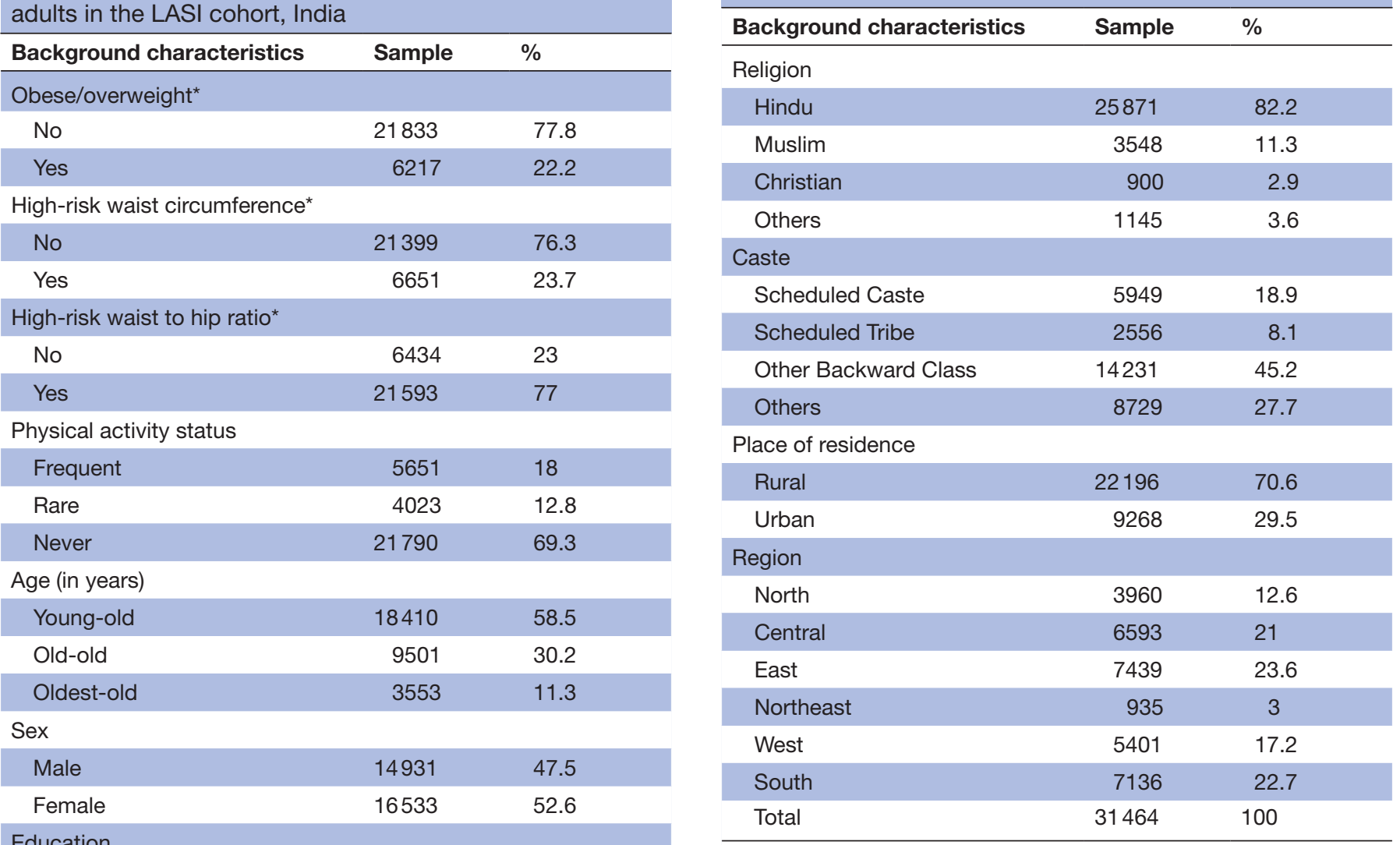

\section{Education}

No education/primary not $\quad 21380$

completed

$\begin{array}{lcc}\text { Primary completed } & 3520 & 11.2 \\ \text { Secondary completed } & 4371 & 13.9 \\ \text { Higher and above } & 2191 & 7\end{array}$

Marital status

$\begin{array}{lrr}\text { Currently married } & 19391 & 61.6 \\ \text { Widowed } & 11389 & 36.2 \\ \text { Others } & 684 & 2.2\end{array}$

Working status

\begin{tabular}{lrl} 
Working & 9680 & 30.8 \\
Retired & 13470 & 42.8 \\
Not working & 8314 & 26.4 \\
Tobacco consumption & & \\
No & 18964 & 60.3 \\
Yes & 12500 & 39.7 \\
Alcohol consumption & & \\
No & 26924 & 85.6 \\
Yes & 4540 & 14.4 \\
MPCE quintile & & \\
Poorest & 6829 & 21.7 \\
Poorer & 6831 & 21.7 \\
Middle & 6590 & 21 \\
Richer & 6038 & 19.2 \\
Richest & 5175 & 16.5 \\
\hline
\end{tabular}

Continued
Table 1 Continued

*The sample may differ as all older adults did not give consent for measurements.

LASI, Longitudinal Aging Study in India; MPCE, monthly per capita consumption expenditure.

overweight/obese. Nearly, a quarter of the older adults had high-risk waist circumference, while about 8 in 10 older adults had high-risk waist to hip ratio. Around $69 \%$ of older adults never did physical activity, while only $18 \%$ did frequent physical activities. Around $62 \%$ of older adults were currently married and $36 \%$ were widowed. In the working status category, about $43 \%$ of older adults were retired, while around $31 \%$ were presently working. Older adults who consumed tobacco and alcohol were around $40 \%$ and $14 \%$, respectively.

Table 2 shows the percentage of older adults suffering from multimorbidity in the LASI cohort. It was found that nearly $43 \%$ of older adults who were overweight/obese had multimorbidity. About $42 \%$ and $26 \%$ of older adults who had high-risk waist circumference and high-risk waist to hip ratio, respectively, were suffering from multimorbidity. About $27 \%$ of older adults who never did physical activities had multimorbidity. The status of multimorbidity among older adults showed an increasing trend with rising educational status. About $26 \%$ of older adults who were widowed were suffering from multimorbidity. The share of older adults suffering from multimorbidity was directly proportional to the MPCE quintile. Among the religious groups, the share of older adults suffering from multimorbidity was highest and lowest among Christians 
Table 2 Percentage of older adults suffering from multimorbidity in the LASI cohort, India

\begin{tabular}{|c|c|c|}
\hline Background characteristics & $\%$ & $P$ value \\
\hline Obese/overweight & & 0.001 \\
\hline No & 18.4 & \\
\hline Yes & 42.6 & \\
\hline High-risk waist circumference & & 0.001 \\
\hline No & 18.1 & \\
\hline Yes & 42.1 & \\
\hline High-risk waist to hip ratio & & 0.001 \\
\hline No & 16.2 & \\
\hline Yes & 26 & \\
\hline Physical activity status & & 0.001 \\
\hline Frequent & 17 & \\
\hline Rare & 15.8 & \\
\hline Never & 27.2 & \\
\hline Age (in years) & & 0.001 \\
\hline Young-old & 22.8 & \\
\hline Old-old & 25.8 & \\
\hline Oldest-old & 24.5 & \\
\hline Sex & & 0.001 \\
\hline Male & 22.2 & \\
\hline Female & 25.4 & \\
\hline Education & & 0.001 \\
\hline No education/primary not completed & 19.7 & \\
\hline Primary completed & 30.1 & \\
\hline Secondary completed & 33.6 & \\
\hline Higher and above & 35.2 & \\
\hline Marital status & & 0.044 \\
\hline Currently married & 23.1 & \\
\hline Widowed & 25.6 & \\
\hline Others & 18.9 & \\
\hline Working status & & 0.001 \\
\hline Working & 13.6 & \\
\hline Retired & 26.9 & \\
\hline Not working & 30.9 & \\
\hline Tobacco consumption & & 0.001 \\
\hline No & 26.7 & \\
\hline Yes & 19.6 & \\
\hline Alcohol consumption & & 0.001 \\
\hline No & 24.6 & \\
\hline Yes & 19.8 & \\
\hline MPCE quintile & & 0.001 \\
\hline Poorest & 16.6 & \\
\hline Poorer & 20.2 & \\
\hline Middle & 22.2 & \\
\hline Richer & 27.9 & \\
\hline Richest & 35.9 & \\
\hline
\end{tabular}

Continued
Table 2 Continued

\begin{tabular}{lll}
\hline Background characteristics & $\%$ & P value \\
\hline Religion & & 0.001 \\
Hindu & 23.2 & \\
Muslim & 26 & \\
Christian & 31.2 & \\
Others & 27.6 & \\
Caste & & 0.001 \\
Scheduled Caste & 19.5 & \\
Scheduled Tribe & 11.1 & \\
Other Backward Class & 24.9 & \\
Others & 29 & \\
Place of residence & & 0.001 \\
Rural & 19.1 & \\
Urban & 35.4 & \\
Region & & 0.001 \\
\hline North & 24.4 & \\
Central & 13.5 & \\
East & 22.9 & \\
Northeast & 16 & \\
West & 27.7 & \\
South & 32.4 & \\
\hline Total & 24 & \\
\hline
\end{tabular}

$P$ value based on $\chi^{2}$ test.

LASI, Longitudinal Aging Study in India; MPCE, monthly per capita consumption expenditure.

$(31 \%)$ and Hindus (23\%), respectively. Older adults from Scheduled Tribe $(11.1 \%)$ suffered from the lowest share of multimorbidity among all the caste groups. Among the regions of India, South India (32\%) recorded the highest share of older adults suffering from multimorbidity, while Central India (14\%) recorded the lowest share. Overall about $24 \%$ of older adults in the LASI cohort suffered from multimorbidity.

Table 3 shows a representation of the logistic regression of older adults who were suffering from multimorbidity. It was found that older adults who were overweight/obese were $61 \%$ significantly more likely to have multimorbidity in comparison with those who were not overweight/obese (adjusted OR (AOR): 1.61, CI 1.48 to 1.74). Older adults with high-risk waist circumference and high-risk waist to hip ratio were $66 \%$ (AOR: 1.66 , CI 1.52 to 1.80 ) and $45 \%$ (AOR: 1.45 , CI 1.33 to 1.59 ) significantly more likely to suffer from multimorbidity, respectively, in reference to those who do not have high-risk waist circumference and high-risk waist to hip ratio, respectively. The odds of multimorbidity were significantly higher among older adults who were physically inactive in reference to older adults who were physically active (AOR: 1.33 , CI 1.21 to 1.46). The likelihood of multimorbidity among women was significantly low in comparison with men (AOR: 0.86, 
Table 3 Logistic regression estimates for multimorbidity among older adults in the LASI cohort, India

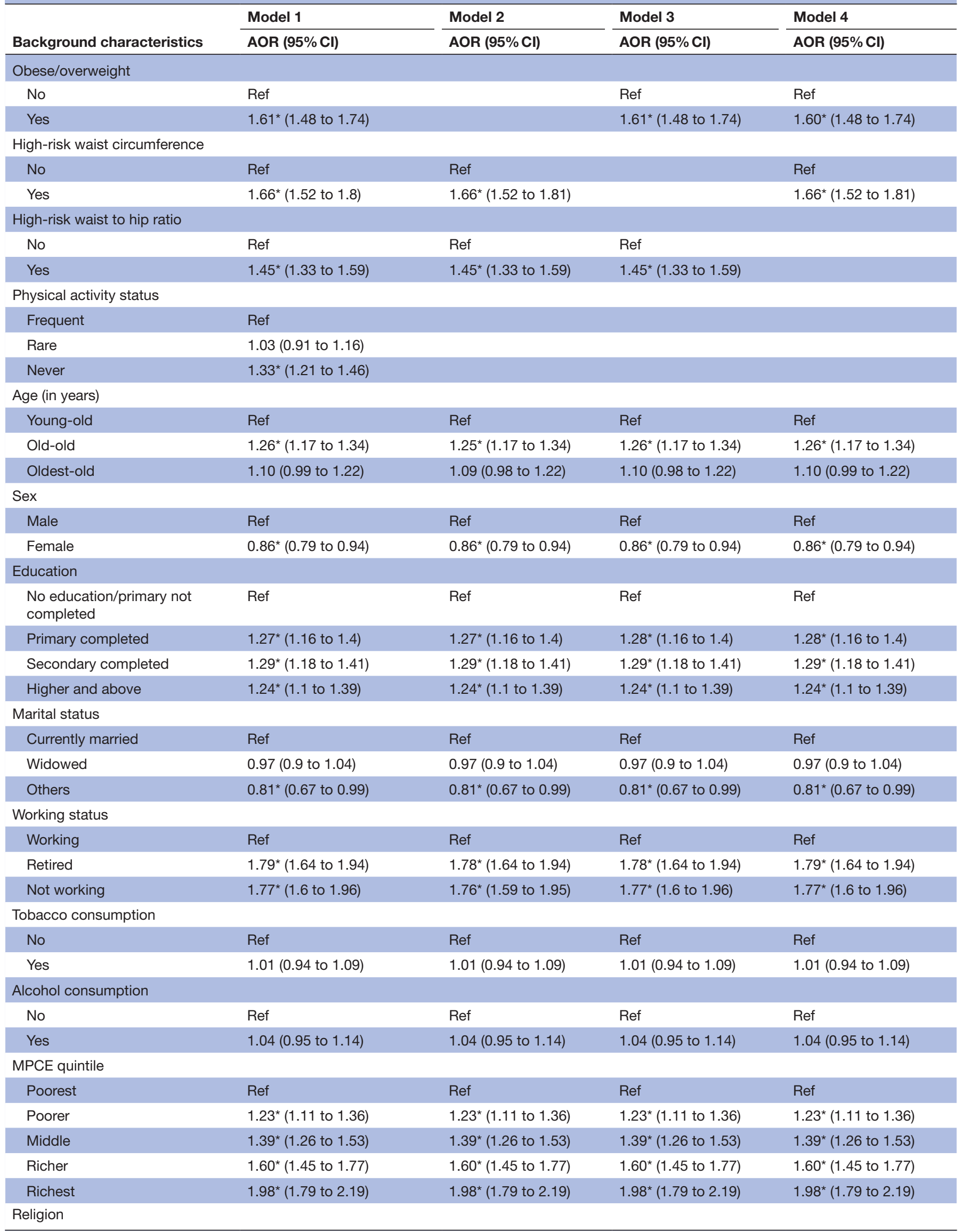


Table 3 Continued

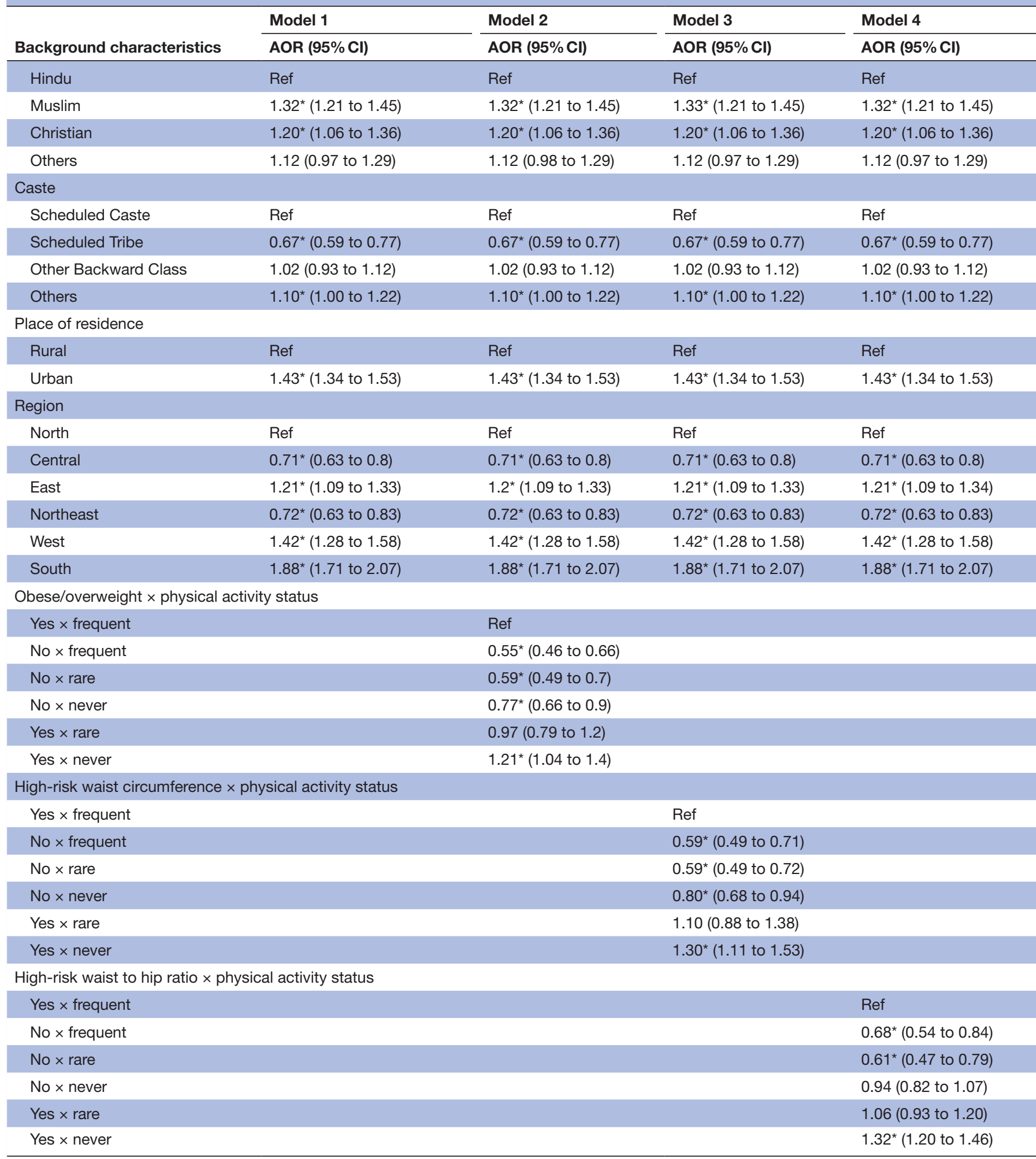

' $x$ ' means interaction.

${ }^{*}$ If $p<0.05$.

AOR, adjusted OR; LASI, Longitudinal Aging Study in India; MPCE, monthly per capita consumption expenditure; Ref, reference.

CI 0.79 to 0.94$)$. The odds of multimorbidity were significantly higher among older adults who were not working in reference to older adults who were currently working (AOR: 1.77, CI 1.6 to 1.96).
Surprisingly, the odds of multimorbidity were $98 \%$ significantly more likely among older adults who were from the richest MPCE quintile in reference to older adults who belonged to the poorest MPCE quintile (AOR: 
1.98 , CI 1.79 to 2.19$)$. Older adults who were from the Scheduled Tribe category were 33\% significantly less likely to suffer from multimorbidity in comparison with older adults who were from the Scheduled Caste category (AOR: 0.67 , CI 0.59 to 0.77 ). Older adults residing in urban areas were $43 \%$ significantly more likely to suffer from multimorbidity in reference to older adults residing in rural areas (AOR: 1.43, CI 1.34 to 1.53). The odds of multimorbidity were significantly higher among older adults of the southern region as compared with older adults of the northern region (AOR: 1.88 , CI 1.71 to 2.07). Older adults who were obese and were physically inactive were $21 \%$ significantly more likely to suffer from multimorbidity in reference to older adults who were obese and were physically active (AOR: 1.21 , CI 1.04 to 1.4). Older adults with high-risk waist circumference and physically inactive status had a $30 \%$ significantly higher likelihood of suffering from multimorbidity in comparison with older adults with high-risk waist circumference and physically active status (AOR: 1.30, CI 1.11 to 1.53 ). Older adults with a high-risk waist to hip ratio and physically inactive status had a $32 \%$ significantly higher likelihood of suffering from multimorbidity in comparison with older adults with a high-risk waist to hip ratio and physically active status (AOR: 1.32, CI 1.20 to 1.46).

\section{DISCUSSION}

Based on a large nationally representative sample of older Indian adults aged 60 and above, the present study has shown the associations between several anthropometric measures and multimorbidity in later years of life. It also examined the interactive effect of physical activity in those associations. The results were statistically significant even after adjusting for a wide range of variables in the study. The higher prevalence of multimorbidity among older men than women was contrary to earlier studies that found a female disadvantage in the co-occurrence of multiple diseases. ${ }^{46} 47$ This differential can be explained by the survival bias that suggests that women who survive may have a better health condition than men who have a shorter life expectancy. ${ }^{48}$

In concordance with a growing body of research that is based on several cross-sectional as well as longitudinal data sets, in the present study, lack of physical activity was associated with a higher likelihood of multimorbidity. ${ }^{49-51}$ There is also a likely reverse causal pathway by which chronic conditions contribute to physical inactivity, increasing the risk of sedentary lifestyles, which in turn could increase the risk of additional chronic conditions such as raised cholesterol and diabetes, producing a vicious cycle between multimorbidity and physical inactivity. On the other hand, results of the study on other unhealthy lifestyle factors such as smoking and alcohol consumption showing no association with multimorbidity are at variance with multiple studies that found smoking habit and drinking as risk factors for the simultaneous presence of two-plus chronic conditions. ${ }^{52-54}$ The finding, however, concurs with a recent study that found an association of smoking and alcohol drinking only in combination with other lifestyle factors. ${ }^{55}$

Of the risk factors examined, obesity/overweight, highrisk waist circumference and high-risk waist to hip ratio were also associated with multimorbidity. Consistent with previous studies, multimorbidity was reported more often by older adults whose obesity-related anthropometric measures were found to be at risk. ${ }^{56-58}$ Further, waist to hip ratio and waist circumference are shown to be more sensitive among several anthropometric indices of obesity while screening for multimorbidity. ${ }^{59-61}$ The present study, in line with earlier studies, found a positive association between both measures and multimorbidity. ${ }^{37}$ Thus, results confirm the association of obesity-related anthropometric measures with multimorbidity that has been repeatedly shown in previous studies. ${ }^{49} 6263$ Although we have adjusted for many of the sociodemographic and lifestyle variables to minimise reverse causality, it is possible to construct a reverse relationship of multimorbidity being the cause of overweight/obesity. Hence, future prospective longitudinal studies are required to identify causality.

Besides, studies have revealed the independent associations of obesity and other related high-risk body measures with physical inactivity. ${ }^{64-67}$ Results of the statistical tests on interactions of obesity-related measures with physical activity in our study show that multimorbidity was more prevalent among older adults who were obese/overweight or at risk of waist to hip ratio and waist circumference with non-performance of any physical activity. The findings of the current analysis which apply to an older population of a developing country highlight the urgent need for further investigation of the effectiveness of physical activity in the management of chronic diseases in lowincome and middle-income countries.

Further, the association between multimorbidity and age is well documented in the literature. Consistently, the current analysis shows that a higher age group is a risk factor for multimorbidity and supports the notion that the additional life years may constitute an increased chance of acquiring other chronic conditions. ${ }^{23}{ }^{46}$ With respect to socioeconomic patterning of multimorbidity, there are inconsistencies in developing countries regarding whether it is concomitant to the wealthy with a lesser impact on the poor or present among the population across all the socioeconomic spectrum. ${ }^{30} 68-70$ However, the present study found that multimorbidity tends to be higher among individuals with higher levels of education, belonging to households with higher wealth quintiles and non-Scheduled Caste/Scheduled Tribe. The finding is consistent with previous studies that have shown statistically significant positive associations between socioeconomic variables such as education, household wealth and higher social groups and the prevalence of multimorbidity. ${ }^{71}$

The strengths of the present study include the large nationally representative sample of older population and objective obesity-related measures. There were also some 
limitations. First, the cross-sectional design of the study makes it impossible to establish the observed directions of the relationships. Another limitation of the study is that it uses a relatively simple definition of counting diseases for measuring multimorbidity compared with previous studies. ${ }^{72-74}$ Similarly, lifestyle factors were self-reported in the survey data and thus susceptible to measurement error. Also, overweight and obese are not split as separate categories due to relatively small sample size in the latter category and as also found in some other studies. ${ }^{75}$ Finally, as a limitation for physical activity, the descriptors to assess activity in the present study do not include many female biased categories such as various aspects of housework, and the data for women may overestimate the never or rare category in the current analyses.

\section{CONCLUSION}

The high prevalence of multimorbidity implies the need for a holistic approach beyond the management of individual diseases. Given that multimorbidity results in substantial life years lost, for increased quality life years in the older ages it is necessary to understand how to manage co-occurring morbidities simultaneously. While developing health strategies for older adults, physical activity needs to be recognised as a way of minimising comorbidities. Further, the study highlights the importance of using multiple obesity-related measures to predict chronic conditions in the older population.

Contributors Conceived and designed the research paper: SS and TM. Analysed the data: SS and TM. Contributed agents/materials/analysis tools: SS, VJKJ, DD and TM. Wrote the manuscript: SS, VJKJ, DD and TM. Refined the manuscript: SS and TM.

Funding The authors have not declared a specific grant for this research from any funding agency in the public, commercial or not-for-profit sectors.

Competing interests None declared.

Patient consent for publication Not required.

Ethics approval The Indian Council of Medical Research (ICMR) extended the necessary guidelines and ethics approval for undertaking the LASI survey.

Provenance and peer review Not commissioned; externally peer reviewed.

Data availability statement Data may be obtained from a third party and are not publicly available. The study uses secondary data which are available on reasonable request through https://www.iipsindia.ac.in/content/lasi-wave-i.

Open access This is an open access article distributed in accordance with the Creative Commons Attribution Non Commercial (CC BY-NC 4.0) license, which permits others to distribute, remix, adapt, build upon this work non-commercially, and license their derivative works on different terms, provided the original work is properly cited, appropriate credit is given, any changes made indicated, and the use is non-commercial. See: http://creativecommons.org/licenses/by-nc/4.0/.

\section{ORCID iDs}

Shobhit Srivastava http://orcid.org/0000-0002-7138-4916

Vinod Joseph K J http://orcid.org/0000-0001-8783-3969

T Muhammad http://orcid.org/0000-0003-1486-7038

\section{REFERENCES}

1 United Nations, Department of Economic and Social Affairs PD.

Population 2030: demographic challenges and opportunities for sustainable development planning (ST/ESA/SER A/389). United Nations, 2015.

2 James KS. India's demographic change: opportunities and challenges. Science 2011;333:576-80.

$3 \mathrm{Ng} \mathrm{M}$, Fleming T, Robinson M, et al. Global, regional, and national prevalence of overweight and obesity in children and adults during 1980-2013: a systematic analysis for the global burden of disease study 2013. Lancet 2014;384:766-81.

4 Barnett K, Mercer SW, Norbury M, et al. Epidemiology of multimorbidity and implications for health care, research, and medical education: a cross-sectional study. Lancet 2012;380:37-43.

5 Kingston A, Robinson L, Booth $\mathrm{H}$, et al. Projections of multimorbidity in the older population in England to 2035: estimates from the population ageing and care simulation (PACSim) model. Age Ageing 2018;47:374-80.

6 World Health Organization. Multimorbidity. technical series on safer primary care. World Health Organization, 2016.

7 Harridge SDR, Lazarus NR. Physical activity, aging, and physiological function. Physiology 2017;32:152-61.

8 Duggal NA, Niemiro G, Harridge SDR, et al. Can physical activity ameliorate immunosenescence and thereby reduce age-related multi-morbidity? Nat Rev Immunol 2019;19:563-72.

9 Francischetti EA, Genelhu VA. Obesity-hypertension: an ongoing pandemic. Int J Clin Pract 2007;61:269-80.

10 Defay R, Delcourt C, Ranvier M, et al. Relationships between physical activity, obesity and diabetes mellitus in a French elderly population: the polA study. Int J Obes 2001;25:512-8.

11 GBD 2015 Obesity Collaborators, Afshin A, Forouzanfar MH, et al. Health effects of overweight and obesity in 195 countries over 25 years. N Engl J Med 2017;377:13-27.

12 Skivington K, Katikireddi SV, Leyland AH, et al. Risk factors for multimorbidity: a multilevel analysis of a longitudinal cohort from Scotland. Eur J Public Health 2015;25:ckv167.020.

13 Vogeli C, Shields AE, Lee TA, et al. Multiple chronic conditions: prevalence, health consequences, and implications for quality, care management, and costs. J Gen Intern Med 2007;22 Suppl 3:391-5.

14 Barry VW, Baruth M, Beets MW, et al. Fitness vs. fatness on all-cause mortality: a meta-analysis. Prog Cardiovasc Dis 2014;56:382-90.

15 Gopinath B, Kifley A, Flood VM, et al. Physical activity as a determinant of successful aging over ten years. Sci Rep 2018;8:10522.

16 Gleeson M, Bishop NC, Stensel DJ, et al. The anti-inflammatory effects of exercise: mechanisms and implications for the prevention and treatment of disease. Nat Rev Immunol 2011;11:607-15.

17 Gourlan MJ, Trouilloud DO, Sarrazin PG. Interventions promoting physical activity among obese populations: a meta-analysis considering global effect, long-term maintenance, physical activity indicators and dose characteristics. Obes Rev 2011;12:e633-45.

18 Sundquist K, Qvist J, Sundquist J, et al. Frequent and occasional physical activity in the elderly: a 12-year follow-up study of mortality. Am J Prev Med 2004;27:22-7.

19 Mummery WK, Kolt G, Schofield G, et al. Associations between physical activity and other lifestyle behaviors in older new Zealanders. J Phys Act Health 2007;4:412-23.

20 Asp M, Simonsson B, Larm P, et al. Physical mobility, physical activity, and obesity among elderly: findings from a large populationbased Swedish survey. Public Health 2017;147:84-91.

21 Surtees PG, Wainwright NWJ, Khaw K-T. Obesity, confidant support and functional health: cross-sectional evidence from the EPICNorfolk cohort. Int J Obes Relat Metab Disord 2004;28:748-58.

22 Chau D, Cho LM, Jani P, et al. Individualizing recommendations for weight management in the elderly. Curr Opin Clin Nutr Metab Care 2008;11:27-31.

23 Marengoni A, Angleman S, Melis R, et al. Aging with multimorbidity: a systematic review of the literature. Ageing Res Rev 2011;10:430-9.

24 Bertheussen GF, Romundstad PR, Landmark T, et al. Associations between physical activity and physical and mental health--a HUNT 3 study. Med Sci Sports Exerc 2011;43:1220-8.

25 Hupin D, Roche F, Gremeaux V, et al. Even a low-dose of moderateto-vigorous physical activity reduces mortality by $22 \%$ in adults aged $\geq 60$ years: a systematic review and meta-analysis. Br J Sports Med 2015;49:1262-7.

26 Vancampfort D, Smith L, Stubbs B, et al. Associations between active travel and physical multi-morbidity in six low- and middleincome countries among community-dwelling older adults: a crosssectional study. PLoS One 2018;13:e0203277.

27 Salisbury C, Johnson L, Purdy S, et al. Epidemiology and impact of multimorbidity in primary care: a retrospective cohort study. $\mathrm{Br} J$ Gen Pract 2011;61:e12-21.

28 Mini GK, Thankappan KR. Pattern, correlates and implications of non-communicable disease multimorbidity among older adults 
in selected Indian states: a cross-sectional study. BMJ Open 2017;7:e013529.

29 Banjare P, Pradhan J. Socio-Economic inequalities in the prevalence of multi-morbidity among the rural elderly in Bargarh district of Odisha (India). PLoS One 2014;9:e97832.

30 Arokiasamy P, Uttamacharya JK. Multi-morbidity, functional limitations, and self-rated health among older adults in India: crosssectional analysis of LASI pilot survey, 2010. SAGE Open 2015;5.

31 Prados-Torres A, Poblador-Plou B, Calderón-Larrañaga A, et al. Multimorbidity patterns in primary care: interactions among chronic diseases using factor analysis. PLoS One 2012;7:e32190.

32 Yadav S, Arokiasamy P. Understanding epidemiological transition in India. Glob Health Action 2014;7:23248.

33 Khokhar A, Mehra M. Life style and morbidity profile of geriatric population in an urbans community of Delhi. Indian $\mathrm{J} \mathrm{Med} \mathrm{Sci}$ 2001;55:609-15.

34 International Institute for Population Sciences (IIPS), NPHCE, MoHFW, Harvard T. H. Chan School of Public Health (HSPH), The University of Southern California (USC). Longitudinal ageing study in India (LASI) wave 1. India report. Mumbai, India, 2020.

35 McKenna SP. Measuring patient-reported outcomes: moving beyond misplaced common sense to hard science. BMC Med 2011;9:86.

36 WHO. Obesity and overweight: fact sheet. who media cent, 2016.

37 Zhang J, Xu L, Li J, et al. Association between obesity-related anthropometric indices and multimorbidity among older adults in Shandong, China: a cross-sectional study. BMJ Open 2020;10:e036664.

$38 \mathrm{McHugh}$ ML. The chi-square test of independence. Biochem Medica 2012.

39 Connelly L. Chi-Square test. MEDSURG Nursing 2019.

40 Osborne J, King JE. Binary Logistic Regression. In: Best practices in quantitative methods. SAGE Publications, Inc, 2011: 358-84.

41 Chauhan S, Srivastava S, Kumar P, et al. Interaction of substance use with physical activity and its effect on depressive symptoms among adolescents. J Subst Use 2020:1-7.

42 Muhammad T, Govindu M, Srivastava S. Relationship between chewing tobacco, smoking, consuming alcohol and cognitive impairment among older adults in India: a cross-sectional study. BMC Geriatr 2021;21:85.

43 Srivastava S, Muhammad T. Violence and associated health outcomes among older adults in India: a gendered perspective. SSM Popul Health 2020;12:100702.

44 Patel R, Marbaniang SP, Srivastava S, et al. Gender differential in low psychological health and low subjective well-being among older adults in India: with special focus on childless older adults. PLOS One 2021;16:e0247943.

45 Van Der Weele TJ, Knol MJ. A tutorial on interaction. Epidemiol Method 2014:3:33-72.

46 Violan C, Foguet-Boreu Q, Flores-Mateo G, et al. Prevalence, determinants and patterns of multimorbidity in primary care: a systematic review of observational studies. PLoS One 2014;9:e102149.

47 de Almeida MGN, Nascimento-Souza MA, Lima-Costa MF, et al. Lifestyle factors and multimorbidity among older adults (ELSI-Brazil). Eur J Ageing 2020;17:521-9.

48 Salomon JA, Wang H, Freeman MK, et al. Healthy life expectancy for 187 countries, 1990-2010: a systematic analysis for the global burden disease study 2010. The Lancet 2012;380:2144-62.

49 de S Santos Machado V, Valadares ALR, Costa-Paiva LH, et al. Aging, obesity, and multimorbidity in women 50 years or older: a population-based study. Menopause 2013;20:818-24.

50 Autenrieth CS, Kirchberger I, Heier M, et al. Physical activity is inversely associated with multimorbidity in elderly men: results from the KORA-Age Augsburg study. Prev Med 2013;57:17-19.

51 Dhalwani NN, O'Donovan G, Zaccardi F, et al. Long terms trends of multimorbidity and association with physical activity in older English population. Int J Behav Nutr Phys Act 2016;13:1-9.

52 Stewart D, McCambridge J. Alcohol complicates multimorbidity in older adults. BMJ 2019;365:14304.

53 Kivimäki M, Kuosma E, Ferrie JE, et al. Overweight, obesity, and risk of cardiometabolic multimorbidity: pooled analysis of individual-level data for 120813 adults from 16 cohort studies from the USA and Europe. Lancet Public Health 2017;2:e277-85.

54 Blumental-Perry A. Unfolded protein response in chronic obstructive pulmonary disease: smoking, aging and disease: a sad trifecta. Curr Mol Med 2012;12:883-98.

55 Dhalwani NN, Zaccardi F, O'Donovan G, et al. Association between lifestyle factors and the incidence of multimorbidity in an older English population. J Gerontol A Biol Sci Med Sci 2017;72:528-34.

56 Agborsangaya CB, Ngwakongnwi E, Lahtinen M, et al. Multimorbidity prevalence in the general population: the role of obesity in chronic disease clustering. BMC Public Health 2013;13.

57 Diederichs C, Berger K, Bartels DB. The measurement of multiple chronic diseases--a systematic review on existing multimorbidity indices. J Gerontol A Biol Sci Med Sci 2011;66:301-11.

58 Jovic D, Marinkovic J, Vukovic D. Association between body mass index and prevalence of multimorbidity: a cross-sectional study. Public Health 2016;139:103-11.

59 Ashwell M, Gunn P, Gibson S. Waist-to-height ratio is a better screening tool than waist circumference and BMl for adult cardiometabolic risk factors: systematic review and meta-analysis. Obes Rev 2012;13:275-86.

60 Lo K, Huang Y-Q, Shen G, et al. Effects of waist to height ratio, waist circumference, body mass index on the risk of chronic diseases, all-cause, cardiovascular and cancer mortality. Postgrad Med J 2021;97:306-11.

61 Gómez-Ambrosi J, Silva C, Galofré JC, et al. Body mass index classification misses subjects with increased cardiometabolic risk factors related to elevated adiposity. Int J Obes 2012;36:286-94.

62 Agborsangaya CB, Lau D, Lahtinen M, et al. Multimorbidity prevalence and patterns across socioeconomic determinants: a cross-sectional survey. BMC Public Health 2012;12:201.

63 Fortin M, Haggerty J, Almirall J, et al. Lifestyle factors and multimorbidity: a cross sectional study. BMC Public Health 2014;14:1-8.

64 Bray GA, Frühbeck G, Ryan DH, et al. Management of obesity. Lancet 2016;387:1947-56.

65 Cárdenas Fuentes G, Bawaked RA, Martínez González Miguel Ángel, et al. Association of physical activity with body mass index, waist circumference and incidence of obesity in older adults. Eur $J$ Public Health 2018;28:944-50.

66 Woo J, Leung J, Kwok T. Bmi, body composition, and physical functioning in older adults. Obesity 2007;15:1886-94.

67 Riebe D, Blissmer BJ, Greaney ML, et al. The relationship between obesity, physical activity, and physical function in older adults. $J$ Aging Health 2009;21:1159-78.

68 Boutayeb A, Boutayeb S. The burden of non communicable diseases in developing countries. Int J Equity Health 2005;4:1-8.

69 Pati S, Hussain MA, Swain S, et al. Development and validation of a questionnaire to assess multimorbidity in primary care: an Indian experience. Biomed Res Int 2016;2016:1-9.

70 Pati S, Swain S, Hussain MA, et al. Prevalence and outcomes of multimorbidity in South Asia: a systematic review. BMJ Open 2015;5:e007235.

71 Basu S, King AC. Disability and chronic disease among older adults in India: detecting vulnerable populations through the who SAGE study. Am J Epidemiol 2013;178:1620-8.

72 Hudon C, Fortin M, Vanasse A. Cumulative illness rating scale was a reliable and valid index in a family practice context. $J$ Clin Epidemiol 2005;58:603-8.

73 Valderas JM, Starfield B, Sibbald B, et al. Defining comorbidity: implications for understanding health and health services. Ann Fam Med 2009;7:357-63.

74 Kirchberger I, Meisinger C, Heier M, et al. Patterns of multimorbidity in the aged population. results from the KORA-Age study. PLoS One 2012;7:e30556-7.

75 Coll-Padrós N, León M, Valech N, et al. Physical activity is associated with better global cognition and frontal function in overweight/obese older adults with metabolic syndrome. Eur Rev Aging Phys Act 2019;16:1-8. 